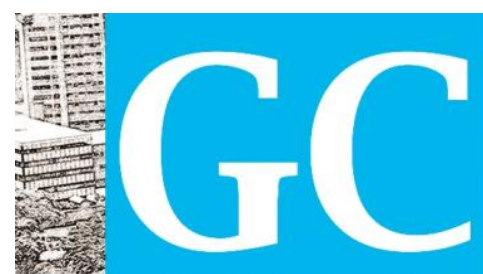

Revista Nacional de

Gerenciamento de Cidades

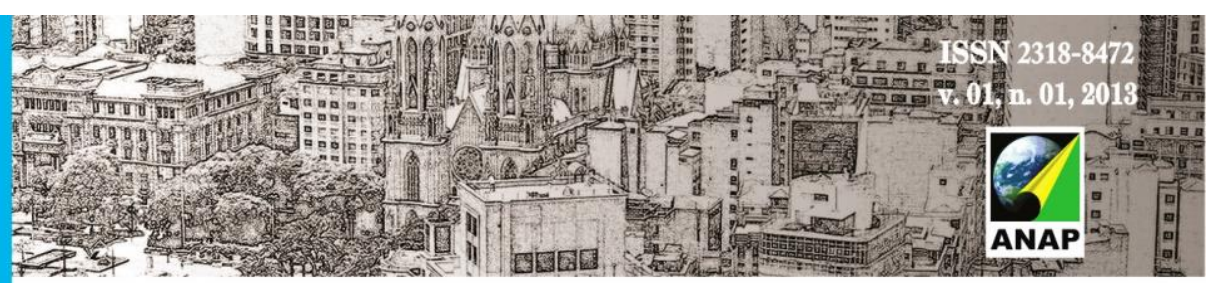

\title{
SELEÇÃO DE INDICADORES DE SUSTENTABILIDADE PARA AVALIAÇÃO DO SISTEMA DE DRENAGEM URBANA
}

\author{
Bárbara Ripol e Silva ${ }^{1}$ \\ Hemerson Pinheiro \\ Deize Dias Lopes ${ }^{3}$
}

RESUMO: É comum observar nas grandes cidades os efeitos negativos causados pelo processo de urbanização desordenado, principalmente aqueles relacionados com o escoamento pluvial. Inundações, erosões da pavimentação das vias e deslizamentos de solo são exemplos dos problemas recorrentes em eventos chuvosos. Para mitigar tais prejuízos, surge a necessidade da utilização de sistemas de drenagem sustentáveis, os quais buscam não modificar o ciclo hidrológico da região, bem como, não transferir impactos decorrentes das precipitações pluviais para jusante. $O$ presente trabalho teve como objetivo desenvolver uma ferramenta de avaliação do sistema de drenagem urbana utilizando indicadores de sustentabilidade selecionados e propostos a partir de informações levantadas na literatura sobre o assunto. Os indicadores definidos devem ser utilizados para avaliações expeditas da drenagem urbana de uma área, pois não fazem uso de levantamentos quantitativos. Os resultados alcançados com a aplicação da ferramenta desenvolvida podem ser utilizados para organizar as informações relacionadas a drenagem urbana e servirem de apoio ao planejamento e tomada de decisões com

\footnotetext{
${ }_{1}^{1}$ Graduanda em Eng. Civil/Universidade Estadual de Londrina. barbararipol@msn.com

2 Doutor em Hidráulica e Saneamento. Prof. Adjunto/UEL. hemersonpinheiro@uel.br

${ }^{3}$ Doutora em Hidráulica e Saneamento. Prof. Associada/UEL. dilopes@uel.br
} 


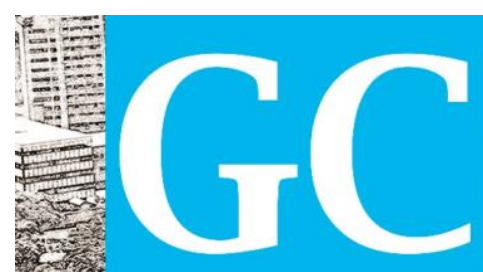

Revista Nacional de

Gerenciamento de Cidades

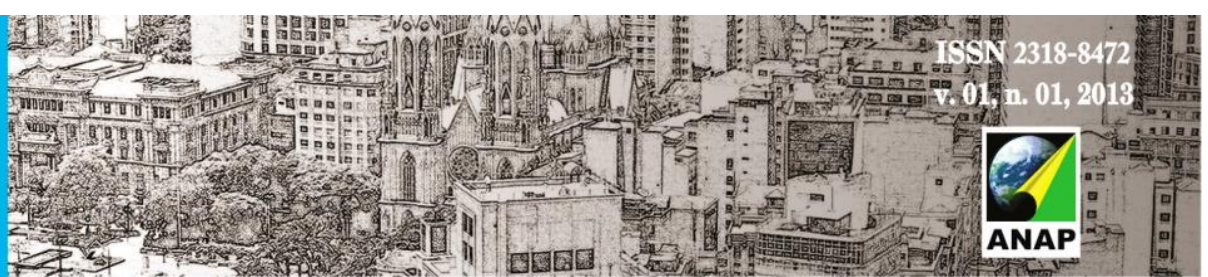

relação às ações a serem adotadas para solução de problemas envolvendo o escoamento das águas pluviais e o sistema de drenagem urbana do local.

Palavras-chave: Drenagem urbana sustentável. Indicadores de sustentabilidade. Águas urbanas. Infraestrutura urbana.

\section{INTRODUÇÃO}

O crescimento desordenado dos centros urbanos provoca alterações no meio ambiente. Grandes áreas naturais tornam-se impermeáveis a medida que a urbanização avança sobre as mesmas, ocasionando a elevação do volume de escoamento superficial das águas pluviais e, consequentemente, gerando enchentes e deslizamentos com maior frequência nas épocas de chuvas (NEVES, 2004). Além do aumento dos volumes escoados, as mudanças no uso e ocupação do solo provocam a redução do tempo de concentração nas bacias e, por isso, contribuem para a elevação dos picos de vazões.

Ademais, o aumento demográfico nas cidades, ao longo dos anos, tem contribuído para a elevação dos volumes de resíduos gerados, os quais, muitas vezes, são depositados em locais inadequados. Tais resíduos acabam se somando aos sedimentos oriundos de erosões e das obras de construção civil e são direcionados à microdrenagem (sarjetas, bocas de lobo e galerias, entre outros dispositivos) e à macrodrenagem (corpos d'água) ocasionando a obstrução e o assoreamento destes, alterando suas características naturais e favorecendo a ocorrência de alagamentos.

As dificuldades vivenciadas atualmente nas cidades, em épocas de chuvas intensas, são consequências de decisões tomadas no passado, tendo como principal fator 

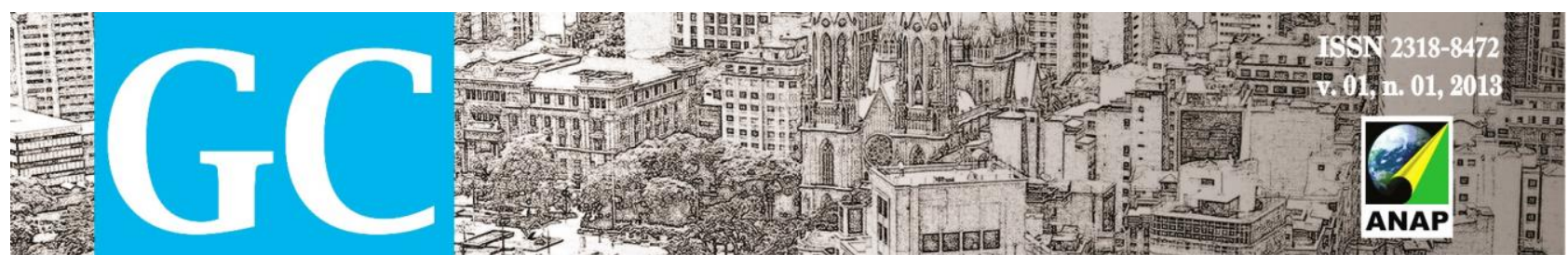

Revista Nacional de

Gerenciamento de Cidades

responsável pela ocorrência desses problemas a ausência de planejamento urbano (NEVES, 2004). Tal planejamento se faz necessário, neste contexto, para que restrições quanto ao uso do solo e ocupação de áreas de risco sejam estabelecidas, assim como diretrizes para a execução de sistemas de drenagem sustentáveis.

A drenagem urbana convencional baseia-se no princípio de que o escoamento superficial provocado pelas precipitações deve ser rapidamente direcionado aos corpos hídricos. O processo de urbanização, intensificado nas últimas décadas, evidenciou os limites da drenagem clássica em relação a sua eficácia (CASTRO, 2002).

Diante desse cenário, surge a necessidade de se projetar sistemas de drenagem mais eficazes por meio da utilização de medidas sustentáveis, visto que elevar a capacidade de escoamento das redes seria muito onerosa e, em condições meteorológicas extremadas ou a longo prazo, talvez esta ação não solucionasse o problema como um todo (DIAS; ANTUNES, 2010).

A drenagem sustentável, um novo conceito que começa a ser aplicado só agora no Brasil, deve respeitar as características do ciclo hidrológico, propiciando a sua manutenção, no tempo, no espaço e no tocante à qualidade da água. Essa abordagem tem como objetivo evitar os problemas originados pela drenagem convencional e mitigar os impactos ambientais decorrentes do processo de urbanização (DIAS; ANTUNES, 2010

A drenagem sustentável possui os seguintes princípios: os novos desenvolvimentos urbanos não podem aumentar a vazão de pico em relação as condições naturais ou prévias, o conjunto da bacia deve ser planejado para o controle do volume das águas e a transferência de impactos para jusante deve ser evitada (TUCCl, 2005).

O presente trabalho visa desenvolver uma ferramenta simplificada para avaliação da evolução, considerando a sustentabilidade ambiental, do sistema de drenagem urbana em pequenas áreas ou bacias, utilizando para este objetivo um conjunto de indicadores 


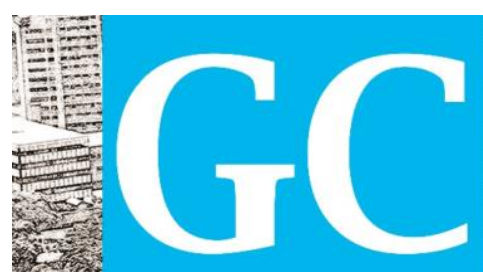

Revista Nacional de

Gerenciamento de Cidades

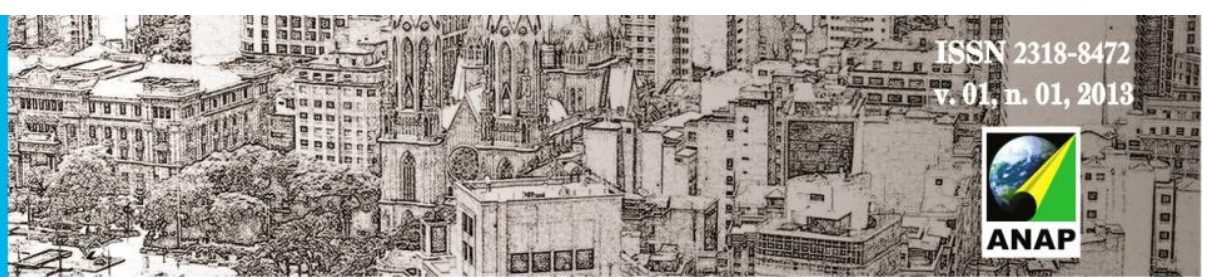

de sustentabilidade selecionados e propostos a partir de informações retiradas da revisão bibliográfica.

\section{DESENVOLVIMENTO}

\subsection{Procedimento Metodológico}

Os procedimentos metodológicos descritos neste tópico foram elaborados tendo como base o objetivo proposto neste trabalho, compondo-se de três etapas. Na primeira etapa foi realizada uma revisão bibliográfica a respeito de indicadores de sustentabilidade, onde foi determinado que a ferramenta de avaliação ambiental elaborada por Romagnolli (2010) seria utilizada como base para a definição de um conjunto de indicadores a serem usados na avaliação de sistemas de drenagem urbana.

$\mathrm{Na}$ segunda etapa foi efetuada uma análise dos indicadores empregados na ferramenta de avaliação mencionada, ocasião na qual alguns indicadores foram eliminados e outros adaptados a fim de que se tornassem mais adequados aos objetivos propostos neste estudo. Além disso, com base nas informações reunidas, novos indicadores foram selecionados e propostos.

$\mathrm{Na}$ terceira etapa foi elaborada uma tabela de avaliação - check list, na qual estão presentes os conjuntos de indicadores selecionados para a análise do sistema de drenagem urbana. Para a agregação dos indicadores em um índice, que indicasse a sustentabilidade do sistema avaliado, optou-se por empregar, o mesmo método matemático utilizado por Romagnolli (2010).

\subsubsection{Indicadores de Sustentabilidade}





Revista Nacional de

Gerenciamento de Cidades

De acordo com Van Bellen (2005 apud ROMAGNOLLI, 2010), o objetivo dos indicadores é agregar e quantificar dados de maneira a deixar a sua relevância mais evidente. Estes simplificam as informações referentes a eventos complexos com 0 propósito de facilitar o processo de comunicação.

No Brasil, o trabalho de construção de Indicadores de Desenvolvimento Sustentável tem como base o movimento internacional liderado pela Comissão para o Desenvolvimento Sustentável (CDS) das Nações Unidas. Tal movimento, desencadeado a partir de 1992, colocou em andamento um programa de trabalho constituído por diversos estudos e intercâmbios de informações, para realizar as disposições encontradas nos capítulos 8 e 40 da Agenda 21, que se referem à relação entre o meio ambiente, 0 desenvolvimento sustentável e informações para a tomada de decisões (IBGE, Indicadores de Desenvolvimento Sustentável, Brasil. 2012).

Os indicadores correspondem a ferramentas compostas por uma ou mais variáveis que, associadas de diversas maneiras, mostram significados mais amplos a respeito dos fenômenos a que se referem. Indicadores de desenvolvimento sustentável são instrumentos imprescindíveis para orientar e auxiliar o acompanhamento, assim como, a avaliação do progresso obtido em direção ao desenvolvimento sustentável. (IBGE, Indicadores de Desenvolvimento Sustentável, Brasil. 2012).

Segundo Romagnolli (2010), os indicadores são parâmetros criteriosamente selecionados, importantes para a reflexão no tocante a determinadas condições do sistema em estudo. Normalmente, para uma melhor interpretação, efetuam-se tratamentos aos dados originais como médias aritméticas, medianas, entre outros.

Os indicadores apresentam múltiplos fins. Agregados através de métodos aritméticos ou regras de decisão permitem a construção de índices que possibilitam a simplificação de alguns parâmetros. Dentre as diversas aplicações de índices e indicadores podem ser citadas: tomada de decisão, alocação de recursos, cumprimento 




Revista Nacional de

Gerenciamento de Cidades

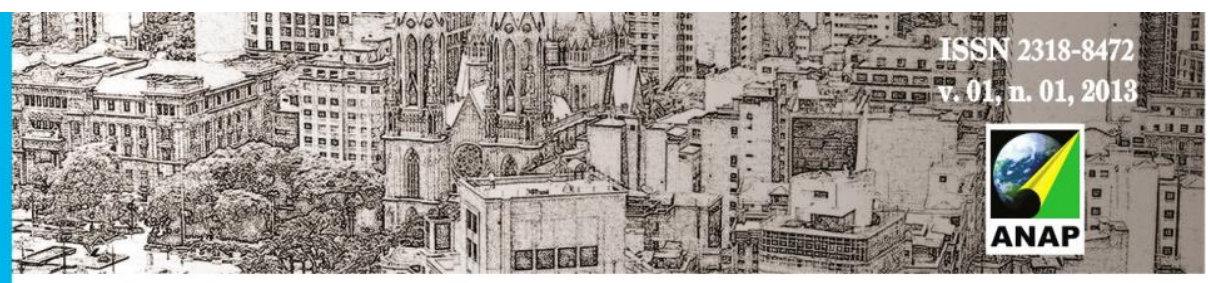

de normas ou critérios legais e investigação científica (COSTA, 2003 apud MARQUES, 2006).

\subsubsection{Construção do Sistema de Indicadores}

Indicadores são medidas formadas por variáveis, ou seja, medições com base em mais de um dado. O somatório de resultados oriundos de atributos individuais podem gerar um índice (LOURENÇO, 2008). Segundo Babbie (1989), para que se realize a construção de indicadores etapas específicas devem ser seguidas, sendo elas: seleção dos itens, avaliação de suas relações empíricas, combinação dos itens no indicador e a validação do indicador (apud LOURENÇO, 2008).

A seguir será apresentada uma breve revisão, proposta por Lourenço (2008), de cada uma das etapas mencionadas acima.

1. Seleção de itens: Cria-se um indicador para medir uma determinada condição. A validade lógica do item é o primeiro critério na seleção.

2. Relações binárias entre itens: $A$ análise das relações binárias entre os itens deve ser realizada a fim de que se determine o tipo e a força da relação empírica que os pares destes possuem entre si.

3. Análise multivariada: O principal objetivo da construção de um indicador é o desenvolvimento de um método adequado para a classificação do sujeito da pesquisa de acordo com alguma variável. Um indicador deve ser capaz de demonstrar distintas avaliações quando empregado em localidades diversas.

4. Pontuação do indicador: Uma vez definidos os itens que irão compor o indicador, duas decisões deverão ser tomadas. A primeira, diz respeito à determinação do intervalo de variação do indicador e do número de casos em cada ponto do índice. Quanto maior for o intervalo entre os dois extremos, menor o número de casos em cada extremo. A segunda decisão refere-se ao valor a ser estabelecido para cada item do 


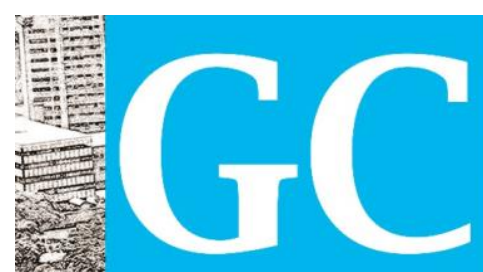

Revista Nacional de

Gerenciamento de Cidades

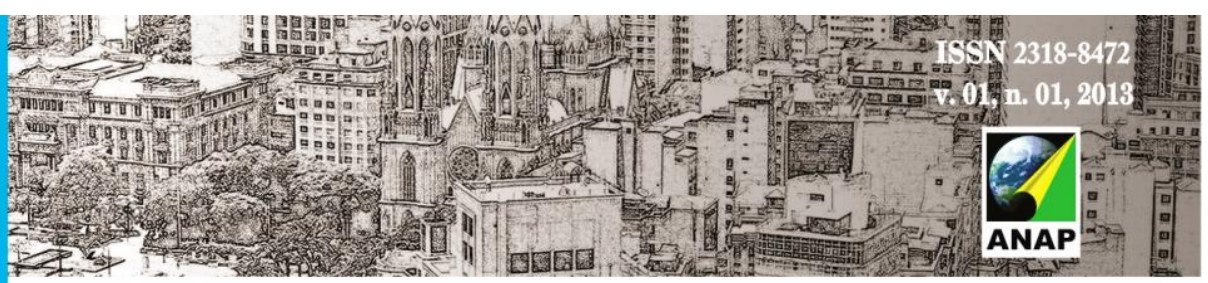

indicador. Neste momento, deverá ser decidido se cada item possuirá o mesmo valor ou se um sistema de pesos será adotado.

\subsubsection{Classificação dos Indicadores: o Modelo Pressão-Estado-Resposta}

O modelo Pressão - Estado - Resposta (PER), desenvolvido pela OECD em 1998 para a avaliação de indicadores ambientais globais, vem sendo aceito e adotado internacionalmente. Tal modelo baseia-se no conceito de causalidade: as atividades humanas provocam pressão no ambiente, o qual sofre alterações em sua qualidade e na quantidade de recursos naturais disponíveis, em outras palavras, o ambiente passa por modificações em seu estado. Por sua vez, a sociedade responde a essas mudanças por meio de políticas ambientais, econômicas ou setoriais. São três os tipos de indicadores ambientais especificados a partir desse modelo (FIDALGO, 2003):

a) indicadores de pressão ambiental: descrevem as pressões oriundas das atividades humanas sobre o ambiente. A quantidade e a qualidade dos recursos naturais são incluídas nestes;

b) indicadores de condições ambientais ou de estado: referem-se à qualidade do ambiente, bem como, a qualidade e a quantidade dos recursos naturais. Estes devem gerar uma visão do estado do ambiente e sua evolução no tempo;

c) indicadores de resposta: são medidas que apresentam a resposta da sociedade em decorrência das modificações ambientais, podendo ser relacionada à mitigação ou prevenção dos efeitos nocivos resultantes das ações do homem sobre o ambiente, à paralisação ou reversão dos danos provocados no meio, e à preservação e conservação da natureza e dos recursos naturais.

\subsubsection{Elaboração do Conjunto de Indicadores}




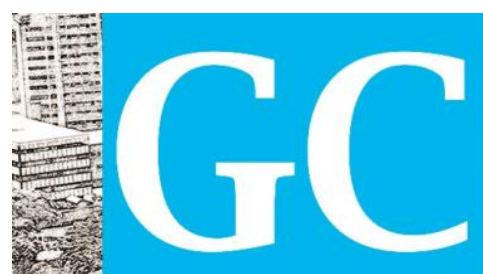

Revista Nacional de

Gerenciamento de Cidades

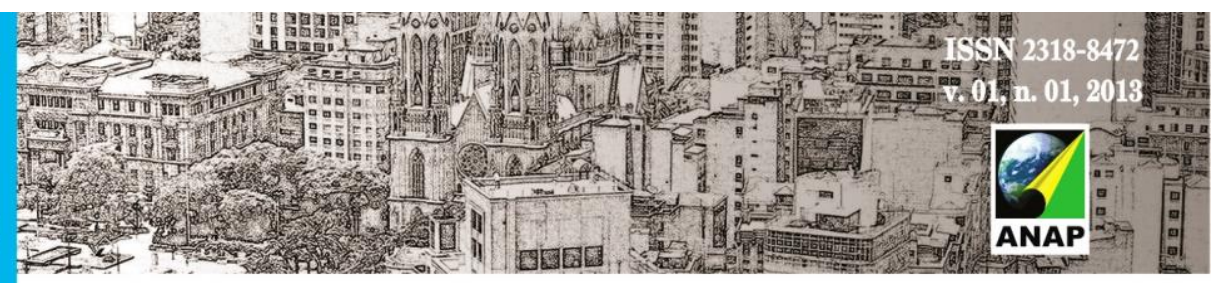

O conjunto de indicadores selecionados teve como base a metodologia desenvolvida por Romagnolli (2010). Por esse motivo, os primeiros indicadores adotados/adaptados foram os do trabalho desenvolvido por essa autora. Os demais foram baseados em indicadores empregados por outros autores ou propostos a partir da revisão bibliográfica, onde novas variáveis de estudo se mostraram relevantes à avaliação do sistema de drenagem urbana, como os indicadores relacionados à limpeza urbana, à coleta de resíduos sólidos e à compatibilização dos cruzamentos das vias.

\subsection{TRATAMENTO DOS DADOS}

O tratamento dos dados foi baseado no proposto pela metodologia seguida por Romagnolli (2010). Tal procedimento visa indicar ou evidenciar se o objeto de avaliação encontra-se favorável ou não à sustentabilidade. O significado de sustentabilidade adotado para este caso, dado por Prescott-Allen (1999 apud VAN BELLEN, 2002), corresponde à condição onde o bem-estar de uma sociedade encontra-se alto e o estresse (oposto do bem-estar ambiental) sobre o sistema ecológico, baixo. Neste trabalho, tal definição será transposta para a drenagem urbana.

O método propõe a definição de valores mínimos e máximos para as variáveis que compõe cada indicador atribuídos de acordo com uma ordem hierárquica do nível mais alto para o mais baixo. $O$ valor 0 (zero) é o atribuído à classe das variáveis que representam a situação de impacto negativo ao meio avaliado. Por sua vez, o valor 5 (cinco) é atribuído a variável que representa a situação ótima ou ideal.

Alcançar valor igual ou maior que a metade da soma relativa ao valor ótimo expressa que a área avaliada apresenta tendência favorável à sustentabilidade. Entretanto, atingir valor menor que a metade da soma relativa ao valor ótimo demonstra tendência desfavorável na área em análise. 


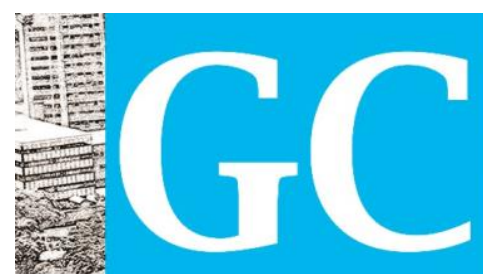

Revista Nacional de

Gerenciamento de Cidades

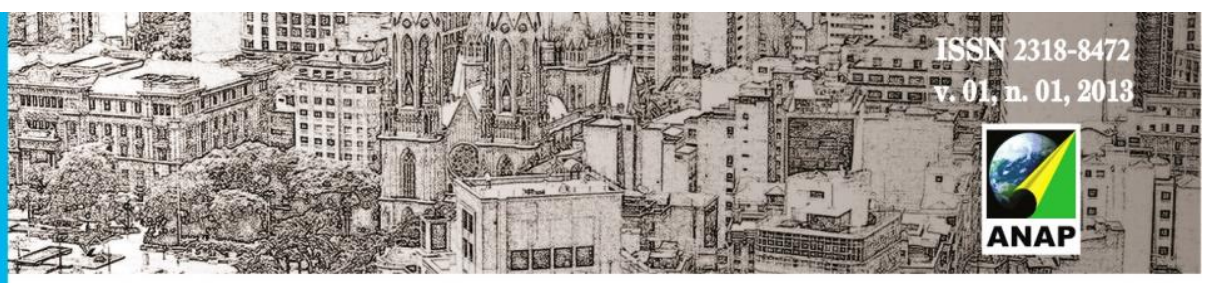

2.3 Resultados

Neste trabalho foi adotado o modelo Pressão - Estado - Resposta (PER), desenvolvido pela OECD (1998) para a classificação dos indicadores.

Após a seleção e classificação do conjunto de indicadores a Tabela 1 foi gerada, na qual os parâmetros a serem avaliados, em cada indicador, e os pesos são apresentados. Nesta tabela, os indicadores de pressão, estado e resposta foram identificados, respectivamente, pela cor amarela, vermelha e verde.

A seguir, será apresentada uma breve consideração a respeito de cada indicador componente da planilha de avaliação gerada (Tabela 01).

- Porcentagem dos lotes que possuem dispositivos de armazenamento e infiltração para água pluvial (valas de infiltração ou similares): a presença desse indicador é justificada, pois deve ser avaliado se as áreas em estudo possuem dispositivos que visam amenizar os impactos negativos da impermeabilização excessiva provocada pela urbanização das regiões.

- Porcentagem dos lotes que possuem dispositivos de captação e reúso de água pluvial: este indicador também avalia se há equipamentos, nas regiões em análise, que auxiliam na redução dos impactos negativos causados pela urbanização na drenagem.

- Existência de diretrizes para a execução do sistema de drenagem urbana: este indicador visa analisar se os dispositivos (bocas de lobo, sarjetas e meio-fio, por exemplo) empregados no sistema de drenagem urbana das áreas em estudo são padronizados e encontram-se posicionados em locais adequados.

- Condições físicas dos equipamentos de drenagem: este indicador visa identificar se os equipamentos de drenagem empregados nas áreas em avaliação estão em boas condições de operação. 




Revista Nacional de

Gerenciamento de Cidades

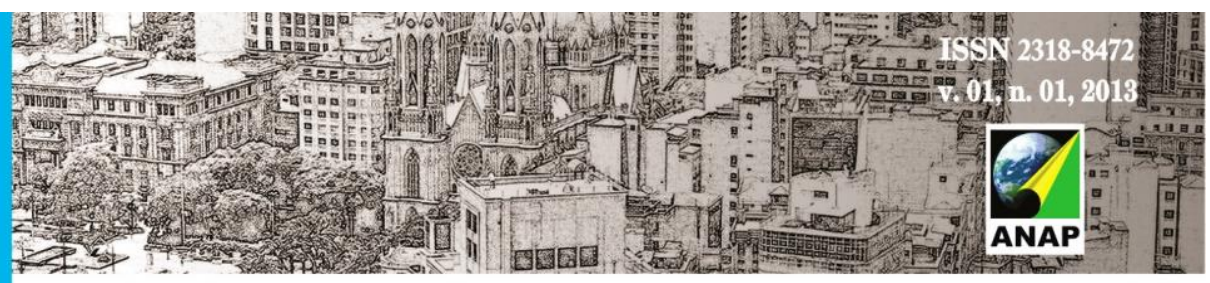

- Tipos de passeios: este faz parte dos indicadores que tem como objetivo verificar a adoção de medidas favoráveis à drenagem sustentável nos sistemas

- Manutenção do sistema de drenagem urbana: este indicador avalia a preocupação das entidades públicas em manter o sistema de drenagem urbana em boas condições de operação, promovendo manutenções regulares nos dispositivos de drenagem.

- Possível erosão na pavimentação e nos acessos ocasionada por escoamento pluvial: este indicador possibilita verificar se os dispositivos de drenagem estão em boas condições, posicionados em locais adequados e se não foram subdimensionados. Caso apresentem um dos problemas citados, o escoamento pluvial pode não estar direcionado adequadamente, originando, assim, erosões nos pavimentos e acessos das vias.

- Possível interferência do escoamento pluvial no trânsito de veículos: este indicador permite avaliar se o sistema de drenagem fornece um bom direcionamento ao escoamento pluvial, de maneira a não interferir no trânsito por ocasião de alagamentos. Em outras palavras, indica se há ou não conforto e segurança para o tráfego durante eventos chuvosos.

- Possível interferência do escoamento pluvial no movimento de pedestres: a adoção deste indicador tem como objetivo analisar se o sistema de drenagem em utilização promove conforto à movimentação de pedestres durante as precipitações pluviais.

- Compatibilização das curvas verticais nos cruzamentos: este indicador avalia se as curvas verticais nas vias em cruzamento foram adequadamente compatibilizadas. A declividade de uma via secundária não pode se sobrepor a de uma principal. Além disso, a compatibilização deve ser tal que o escoamento de uma rua não deságue sobre a outra e, desta forma, não interfira na segurança do tráfego de veículos. 


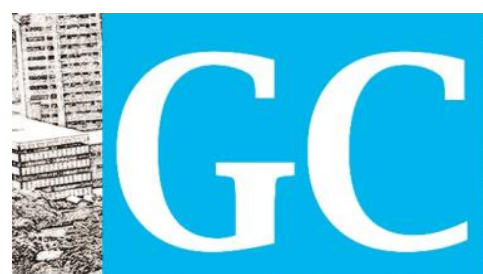

Revista Nacional de

Gerenciamento de Cidades



- Ocorrência de alagamentos: por meio deste indicador, busca-se identificar se há alagamentos nas áreas em análise e com que frequência ocorrem.

- Favorecimento da produção de sedimentos: este indicador tem como objetivo identificar se as regiões em estudo são próximas a àreas que facilitam a produção de sedimentos, tais como, lugares onde o carreamento de solo é favorecido, uma vez que não há proteção superficial (vegetação, por exemplo) para evitar que o material solto seja transportado para o sistema de drenagem.

- Disposição de resíduos sólidos nas vias públicas: este indicador permitirá avaliar se as regiões em análise apresentam locais que possibilitam a disposição clandestina de resíduos. Caso seja observado que sim, existe a possibilidade de que os dispositivos de drenagem, nas áreas em questão, estejam sendo obstruídos e assoreados gradativamente por tais resíduos.

- Frequência da varrição dos passeios públicos: este indicador permite verificar a frequência de limpeza dos passeios, demonstrando se na região há ou não muitos resíduos e sedimentos que acabam por ser transportados até os equipamentos do sistema de drenagem urbana durante a ocorrência de precipitações pluviais.

- Frequência da coleta de lixo: este indicador possibilita a verificação da frequência de coleta de lixo nas regiões, mostrando se esta ocorre ou não. A coleta regular de lixo é fundamental para que os resíduos sejam descartados em locais adequados e não acabem prejudicando o sistema de drenagem urbana. 


\begin{tabular}{|c|c|c|c|c|}
\hline TEMA & INDICADOR & AVALIAÇÃO & A & PESO \\
\hline \multirow{4}{*}{$\mathbf{R}$} & \multirow{4}{*}{$\begin{array}{l}\text { Porcentagem dos lotes que possuem } \\
\text { dispositivos de armazenamento e } \\
\text { infiltração para água pluvial (valas de } \\
\text { infiltração ou similares). }\end{array}$} & $100 \%$ possui & & 5 \\
\hline & & Entre $50 \%$ e $90 \%$ & & 4 \\
\hline & & Inferior a $50 \%$ & & 3 \\
\hline & & Nenhum lote possui dispositivos para armazenamento da água pluvial & & 0 \\
\hline \multirow{3}{*}{$\mathbf{R}$} & \multirow{3}{*}{$\begin{array}{c}\text { Porcentagem dos lotes que possuem } \\
\text { dispositivos de captação e reúso de } \\
\text { água pluvial. }\end{array}$} & $100 \%$ possui & & 5 \\
\hline & & Entre $50 \%$ e $90 \%$ & & 4 \\
\hline & & Nenhum lote possui dispositivos para reúso da água pluvial & & 0 \\
\hline \multirow{2}{*}{$\mathbf{E}$} & \multirow{2}{*}{$\begin{array}{c}\text { Existência de diretrizes para a } \\
\text { execução do sistema de drenagem } \\
\text { urbana. }\end{array}$} & Foram utilizadas diretrizes na execução do sistema de drenagem & & 5 \\
\hline & & Não foram utilizadas diretrizes na execução do sistema de drenagem & & 0 \\
\hline \multirow{2}{*}{$\mathbf{E}$} & \multirow{2}{*}{$\begin{array}{l}\text { Condições físicas dos equipamentos } \\
\text { de drenagem. }\end{array}$} & Equipamentos em boas condições, de fácil acesso, remoção e manutenção & & 5 \\
\hline & & Equipamentos em más condições, de difícil acesso, remoção e manutenção & & 0 \\
\hline $\mathbf{R}$ & Tipos de passeios. & Passeios que permitem alguma infiltração de água pluvial & & 5 \\
\hline \multirow{2}{*}{$\mathbf{R}$} & \multirow{4}{*}{$\begin{array}{c}\text { Manutenção do sistema de drenagem } \\
\text { urbana. }\end{array}$} & Há manutenções regulares & & 5 \\
\hline & & Há manutenções apenas após eventos críticos & & 4 \\
\hline \multirow{2}{*}{$\mathbf{P}$} & & Manutenção deficiente e com dispositivos construídos erroneamente & & 3 \\
\hline & & Não há manutenções & & 0 \\
\hline \multirow{2}{*}{ E } & \multirow{2}{*}{$\begin{array}{l}\text { Possível erosão na pavimentação e } \\
\text { nos acessos ocasionada por } \\
\text { escoamento pluvial. }\end{array}$} & Não há evidências de processos erosivos ocasionados pelo escoamento das águas pluviais & & 5 \\
\hline & & Há evidências de processos erosivos ocasionados pelo escoamento das águas pluviais & & 0 \\
\hline \multirow{2}{*}{$\mathbf{E}$} & \multirow{2}{*}{$\begin{array}{l}\text { Possível interferência do escoamento } \\
\text { pluvial no trânsito de veículos. }\end{array}$} & Não há interferência & & 5 \\
\hline & & Há interferência & & 0 \\
\hline
\end{tabular}

Fonte: A autora 


\begin{tabular}{|c|c|c|c|c|}
\hline TEMA & INDICADOR & AVALIAÇÃO & A & PESO \\
\hline \multirow{2}{*}{ E } & \multirow{2}{*}{$\begin{array}{l}\text { Possível interferência do escoamento pluvial no } \\
\text { movimento de pedestres. }\end{array}$} & Não há interferência & & 5 \\
\hline & & Há interferência & & 0 \\
\hline \multirow{2}{*}{ E } & \multirow{2}{*}{$\begin{array}{c}\text { Compatibilização das curvas verticais nos } \\
\text { cruzamentos }\end{array}$} & Há compatibilização dos cruzamentos & & 5 \\
\hline & & Não há compatibilização dos cruzamentos & & 0 \\
\hline \multirow{3}{*}{ E } & \multirow{3}{*}{ Ocorrência de alagamentos. } & Não ocorrem alagamentos & & 5 \\
\hline & & Ocorrem alagamentos em eventos chuvosos muito intensos & & 3 \\
\hline & & Sempre ocorrem alagamentos quando há precipitação pluvial & & 0 \\
\hline \multirow{3}{*}{$\mathbf{P}$} & \multirow{3}{*}{$\begin{array}{c}\text { Favorecimento da produção de sedimentos } \\
\text { (locais onde o solo não está protegido } \\
\text { superficialmente) }\end{array}$} & Não há locais onde o carreamento de solo é favorecido & & 5 \\
\hline & & Há poucos locais onde o carreamento de solo é favorecido & & 3 \\
\hline & & Há muitos locais onde o carreamento de solo é favorecido & & 0 \\
\hline \multirow{2}{*}{$\mathbf{P}$} & \multirow{2}{*}{$\begin{array}{l}\text { Disposição de resíduos sólidos nas vias } \\
\text { públicas. }\end{array}$} & Não há descarte de resíduos sólidos nas vias públicas & & 5 \\
\hline & & Há descarte de resíduos sólidos nas vias públicas & & 0 \\
\hline \multirow{2}{*}{$\mathbf{R}$} & \multirow{4}{*}{ Frequência da varrição dos passeios públicos. } & Diária & & 5 \\
\hline & & 3 vezes por semana & & 4 \\
\hline \multirow{2}{*}{$\mathbf{P}$} & & Semanal & & 3 \\
\hline & & Não há varrições & & 0 \\
\hline \multirow{2}{*}{$\mathbf{R}$} & \multirow{4}{*}{ Frequência da coleta de lixo. } & Diária & & 5 \\
\hline & & 3 vezes por semana & & 4 \\
\hline \multirow{2}{*}{$\mathbf{P}$} & & Semanal & & 3 \\
\hline & & Não há coleta de lixo & & 0 \\
\hline & & $\overline{\text { TOTAL }}$ & & 75 \\
\hline
\end{tabular}

Fonte: A autora 


\section{CONCLUSÃO}

Os indicadores definidos neste trabalho devem ser utilizados para avaliações expeditas da drenagem urbana de uma área, pois não fazem uso de levantamentos quantitativos. São determinados a partir de dados de fácil obtenção, não necessitam de recursos financeiros e de pessoal técnico especializado para seu levantamento.

Os resultados alcançados com a aplicação da ferramenta desenvolvida podem ser utilizados para organizar as informações relacionadas a drenagem urbana de uma determinada área da cidade e, ainda, servirem de apoio ao planejamento e tomada de decisões com relação a ações a serem adotadas para solução de problemas envolvendo o sistema de drenagem urbana do local.

A ferramenta deve ser aplicada em diferentes áreas e a partir dos resultados obtidos os indicadores escolhidos devem ser reavaliados, visando melhorar a ferramenta.

\section{REFERÊNCIAS}

AGENDA 21. Conferência das Nações Unidas sobre Meio Ambiente e Desenvolvimento. Disponível em:

<http://www.onu.org.br/rio20/img/2012/01/agenda21.pdf>. Acesso em: 26 jul. 2013.

CASTRO, L. M. A. de. Proposição de indicadores para a avaliação de sistemas de drenagem urbana. 2002. Dissertação (Mestrado em Saneamento, Meio Ambiente e Recursos Hídricos) - Universidade Federal de Minas Gerais, Belo Horizonte, 2002.

\section{DIAS, F. S.; ANTUNES, Patricia T. da S. C. Estudo comparativo de projeto de} drenagem convencional e sustentável para controle de escoamento superficial em ambientes urbanos. 2010. Projeto de Graduação (Graduação em Engenharia Civil) Universidade Federal do Rio de Janeiro, Rio de Janeiro, 2010.

IBGE. Indicadores de Desenvolvimento Sustentável - 2012. Disponível em: <ftp://geoftp.ibge.gov.br/documentos/recursos_naturais/indicadores_desenvolvimento_sus tentavel/2012/ids2012.pdf>. Acesso em: 27 jul. 2013. 
$<$ http://www.unifae.br/publicacoes/pdf/sustentabilidade/marcus_lorenco.pdf>. Acesso em: 27 jul. 2013.

MARQUES, Cláudia Elisabeth Bezerra. Proposta de método para a formulação de planos diretores de drenagem urbana. 2006. Dissertação (Mestrado em Tecnologia Ambiental e Recursos Hídricos) - Universidade de Brasília, Brasília, 2006.

NEVES, D. S. O papel da legislação municipal na drenagem urbana - caso: cidade de São Paulo. 2004. Trabalho de Conclusão de Curso (Graduação em Engenharia Civil com ênfase Ambiental) - Universidade Anhembi Morumbi, São Paulo, 2004.

OCDE. Rumo a um Desenvolvimento Sustentável: Indicadores Ambientais. Tradução de Ana Maria S. F. Teles. Salvador: Centro de Recursos Ambientais (CRA), 2002. 244 p. Tradução de: Vers um développement durable: Indicateurs d'environnement e Towards sustainable development: Environmental indicators. Disponível em:

<http://www.oecd.org/env/indicators-modelling-outlooks/2345364.pdf>. Acesso em: 27 jul. 2013.

ROMAGNOLLI, Renata. Metodologia preliminar de avaliação ambiental, com base no ciclo da água, aplicada ao planejamento urbano em municípios de pequeno porte no norte do Paraná. 2010. 177 f. Dissertação (Mestrado em Engenharia de Edificações e Saneamento) - Universidade Estadual de Londrina, Londrina, 2010.

STEINER, Laura. Avaliação do sistema de drenagem pluvial urbana com aplicação do índice de fragilidade. Estudo de caso: Microbacia do rio Criciúma, SC. 2011. Trabalho de Conclusão de Curso (Graduação em Engenharia Ambiental) - Universidade do Extremo Sul Catarinense, Criciúma, 2011.

VAN BELLEN, Hans Michael. Indicadores de sustentabilidade: uma análise comparativa. 2002. Tese (Doutorado em Engenharia de Produção) - Universidade Federal de Santa Catarina, Florianópolis, 2002. 